\title{
RESGATE E PROPAGAÇÃO VEGETATIVA DE Sequoia sempervirens
}

\author{
Márcio Carlos Navroski ${ }^{1}$, Mariane de Oliveira Pereira ${ }^{2}$, André Felipe Hess ${ }^{1}$, Raul Silvestre ${ }^{1}$, \\ Alessandro Camargo Ângelo ${ }^{3}$, Amanda Johann Fazzini ${ }^{4}$, Allan Antunes Alvarenga ${ }^{4}$ \\ ${ }^{1}$ Universidade do Estado de Santa Catarina, Departamento de Engenharia Florestal, Lages, Santa Catarina, Brasil - \\ marcio.navroski@udesc.br; andre.hess@udesc.br; a2rs@cav.udesc.br \\ ${ }^{2}$ Universidade Federal do Paraná, Programa de Pós-graduação em Engenharia Florestal, Curitiba, Paraná, Brasil - \\ maripereira.florestal@gmail.com \\ ${ }^{3}$ Universidade Federal do Paraná, Departamento de Ciências Florestais, Curitiba, Paraná, Brasil - alessandrocangelo@gmail.com \\ ${ }^{4}$ Universidade do Estado de Santa Catarina, Curso de Engenharia Florestal, Lages, Santa Catarina, Brasil - \\ amanda_johann@hotmail.com; allan_antunez@hotmail.com \\ Recebido para publicação: 13/02/2014 - Aceito para publicação: 03/11/2014
}

\begin{abstract}
Resumo
Objetivou-se com o estudo verificar resgate vegetativo, enraizamento de estacas e adaptação das mudas enraizadas em sistema de minijardim clonal de Sequoia sempervirens. Realizou-se a decepa de cinco indivíduos com 20 anos de idade e após foi contabilizada a capacidade de emissão de brotações. Com as brotações, foram confeccionadas estacas, as quais foram submetidas a diferentes concentrações de ácido indolacético (AIA) $\left(0,2000,4000\right.$ e $\left.6000 \mathrm{mg} . \mathrm{L}^{-1}\right)$. Foram avaliadas a porcentagem de enraizamento e o número e comprimento de raízes 160 dias após o estaqueamento. $\mathrm{O}$ experimento foi instalado em DIC, com 5 repetições de 10 estacas. Após a formação das mudas com as estacas enraizadas, elas foram transplantadas para vasos, para a formação do minijardim clonal. $\mathrm{O}$ resgate vegetativo através da decepa de árvores apresentou potencialidade para produção de estacas de sequoia e revigoramento do material. O uso entre 2000 e 4000 mg. $L^{-1}$ de AIA aumentou a porcentagem de enraizamento e também o número e comprimento de raízes formadas. O minijardim clonal de sequoia mostrou ser uma boa opção para a multiplicação clonal da espécie. A clonagem da sequoia pode auxiliar tanto no melhoramento convencional como em plantios comerciais da espécie, principalmente no Sul do Brasil, local onde encontra condições adequadas para seu crescimento. Palavras-chave: Silvicultura clonal; coníferas; rejuvenescimento; minijardim clonal.
\end{abstract}

\begin{abstract}
Rescue and vegetative propagation of Sequoia sempervirens. The objective of the study to verify the vegetative rescue, rooting cuttings and rooted plants adapt in mini-clonal hedge of Sequoia sempervirens system. Was held coppicing five individuals aged 20 years old and was recorded after the ability to shoot emission. Shoots with different concentrations of indole acetic acid were applied (IAA) $\left(0,2000,4000\right.$ and $\left.6000 \mathrm{mg} . \mathrm{L}^{-1}\right)$ in cuttings made by evaluating the percentage of rooting, number and length of roots 160 days after striking. The experiment was a completely randomized with five replicates of 10 cuttings. After the formation of seedlings with rooted cuttings, these were transplanted to pots for the formation of mini-clonal hedge. The vegetative rescue through coppicing trees showed potential for the production of cuttings sequoia and reinvigoration of the material. The use from 2000 to $4000 \mathrm{mg} . \mathrm{L}^{-1}$ IAA increased rooting percentage and the number and length of roots formed. The mini-clonal hedge of sequoia proved to be a good option for clonal multiplication of the species. Cloning of sequoia can help both conventional breeding and for commercial plantations of the species, especially in southern Brazil, where finds suitable conditions for their growth.
\end{abstract} Keywords: Clonal forestry; conifers; rejuvenation; mini-clonal hedge.

\section{INTRODUÇÃO}

A sequoia (Sequoia sempervirens (D. Don) Endl.) é nativa da metade noroeste dos Estados Unidos, principalmente da costa central e norte da Califórnia, uma região com chuva moderada, inverno rigoroso e verão com nevoeiro, vital para o crescimento da espécie. No local de origem, a espécie é encontrada principalmente em parques e alguns plantios em pequena escala (OLSON et al., 1990).

FLORESTA, Curitiba, PR, v. 45, n. 2, p. 383 - 392, abr. / jun. 2015.

Navroski, M. C. et al.

ISSN eletrônico 1982-4688 / ISSN impresso 0015-3826

383

DOI: $10.5380 /$ rf.v45i2.35407 
No mundo, alguns indivíduos dessa espécie estão entre as plantas que apresentam as maiores alturas, chegando alguns deles a apresentar alturas maiores que 100 metros (COWN, 2008). Desde 1840, a sequoia foi introduzida na América e domesticada com sucesso em muitos países (LIU et al., 2006). No Brasil, foi plantada principalmente para arborização, não sendo encontrados plantios comerciais com a espécie.

Apresenta cerne marrom-avermelhado e alburno quase branco, boa estabilidade dimensional e excelentes características para laminação e fabricação de painéis. Embora possua uma densidade média relativamente baixa $\left(0,31 \mathrm{~g} / \mathrm{cm}^{3}\right)$, comparativamente às outras espécies nativas norte-americanas, sua madeira está entre as mais duráveis (MARCHIORI, 1996). Apresenta extrativos (PIIRTO, 1986), o que torna a madeira mais resistente a fungos e ataque de insetos (COWN, 2008).

A sequoia é uma espécie que apresenta propagação principalmente por sementes. Entretanto, a taxa de germinação das sementes é muito baixa (média de 10\%) e a viabilidade das plântulas também é baixa (BOE, 1974). Além disso, plantas jovens apresentam menor viabilidade das sementes, sendo que a maior viabilidade foi obtida em árvores com 250 anos de idade (OLSON et al., 1990).

Em áreas naturais, conforme Luna (2008), a reprodução por propagação vegetativa é a mais comum. Quando uma árvore é cortada ou queimada, surgem brotações do tronco cortado ou das raízes já estabelecidas, crescendo com mais vigor do que as mudas do sub-bosque. Assim, a informação genética de um indivíduo é a mesma de árvores que habitavam o local a milhares de anos atrás.

$\mathrm{Na}$ produção de mudas, para reduzir os problemas com a baixa germinação e viabilidade das plântulas, pode ser utilizada a propagação vegetativa por estaquia. Entretanto, segundo Liu et al. (2006), a estaquia da sequoia pode apresentar problemas no enraizamento e baixa produção de raízes finas na estaca, o que pode prejudicar a sobrevivência das mudas. Segundo Olson et al. (1990), é possível obter mais de $90 \%$ de enraizamento com o uso de matrizes jovens e uso de irrigação por nebulização. Ainda segundo os autores, estacas de árvores mais velhas são mais difíceis de enraizar. Metcalf (1924) foi o primeiro a descrever o melhor enraizamento de estacas de árvores jovens em relação às de maior idade.

O potencial de enraizamento de estacas e a qualidade das mudas de sequoia são afetados pelo efeito de ciclófise (efeitos do grau de maturação da planta doadora) e topófise (efeitos devidos à posição do corte na arquitetura da planta doadora) (LUNA, 2008). Para facilitar a coleta de brotações viáveis ao enraizamento e atingir maior juvenilidade do material, pode ser utilizado o corte raso das árvores-matrizes e que transmitirá informações genéticas. A realização da decepa de árvores adultas para induzir o crescimento de brotações juvenis e a manutenção da juvenilidade por podas sucessivas visa aumentar a produção de propágulos e manter a juvenilidade dos mesmos (HACKETT, 1987).

Fritz (1950) descobriu que estacas coletadas da porção mais basal das árvores apresentaram melhor enraizamento que ramos terminais ou de galhos, diminuindo também os efeitos do plagiotropismo. No mesmo sentido, Power et al. (1988) encontraram maior enraizamento em estacas coletadas nas brotações basais das árvores. Linhart e Libby (1965) relataram que estacas de sequoia obtidas de brotações basais podem elevar o enraizamento utilizando-se concentrações altas de ácido indolbutírico (AIB) $\left(8.000 \mathrm{mg} \cdot \mathrm{L}^{-1}\right)$.

No Brasil, a espécie encontra condições adequadas para o desenvolvimento principalmente no Sul do país, destacando-se os locais mais altos, como a serra gaúcha e o planalto-serra catarinense, locais em que o cultivo de outras espécies, como o Eucalyptus, é prejudicado em razão da ocorrência de fortes geadas. Dessa forma, a seleção de indivíduos superiores e a sua propagação podem alavancar o cultivo dessa espécie nessas regiões e se tornar mais uma opção para o silvicultor.

O objetivo do trabalho foi verificar o resgate vegetativo, enraizamento de estacas em função de doses de AIA (ácido indolacético) e adaptação das mudas enraizadas em sistema de minijardim clonal de Sequoia sempervirens.

\section{MATERIAL E MÉTODOS}

O material vegetal foi proveniente de um plantio de 20 indivíduos realizado em 1992, localizado em área pertencente à Empresa de Pesquisa Agropecuária e Extensão Rural de Santa Catarina (EPAGRI), localizada no município de São Joaquim, SC, situado na Serra Catarinense a aproximadamente 1.300 metros de altitude. As mudas para a formação do plantio foram produzidas a partir de sementes originárias de matrizes dos Estados Unidos, desconhecendo-se a procedência mais precisa. 
De acordo com a classificação de Köppen, o clima de São Joaquim é do tipo Cfb, subtropical ou temperado, com verão fresco e baixa temperatura no inverno, com temperatura média anual de $13,4{ }^{\circ} \mathrm{C}$ e precipitação média anual de $1.713 \mathrm{~mm}$ (VERÍSSIMO, 2006).

Para o resgate do material vegetal, foi realizada a decepa em cinco indivíduos do plantio, apresentando altura média de 15,2 metros e DAP médio de $55 \mathrm{~cm}$. O corte foi realizado a uma altura de $10 \mathrm{~cm}$ do solo. Cinco meses após a decepa, foi realizada a coleta das brotações, sendo estas transportadas em caixa de isopor contendo gelo ao fundo e cobertas por folhas de jornal umedecido com água, até o Viveiro Florestal do Centro de Ciências Agroveterinárias (CAV) da Universidade do Estado de Santa Catarina (UDESC).

Das brotações, foram preparadas estacas com aproximadamente dez centímetros de comprimento. A porção basal foi cortada em bisel e a porção superior incisada transversalmente, mantendo-se um par de folhas cortadas pela metade. Para tratamento fitossanitário, as estacas foram mergulhadas durante 5 min. em 2 litros de solução de hipoclorito de sódio a 1,5\% de cloro ativo, seguido de imersão em água corrente durante $5 \mathrm{~min}$. e, por fim, imersão em fungicida com princípio ativo Benomyl (5\%), por $5 \mathrm{~min}$.

As estacas foram imersas em soluções hidroalcoólicas de diferentes concentrações de ácido indolacético (AIA) (tratamentos), permanecendo a base das estacas em contato com a solução por um período de 10 segundos. O tratamento-controle foi veiculado com solução hidroalcoólica isenta de regulador vegetal, durante o mesmo período.

$\mathrm{O}$ experimento foi conduzido em delineamento inteiramente casualizado, com quatro tratamentos, compostos pelas diferentes concentrações de AIA. Os tratamentos foram: testemunha (sem presença da auxina), $2000 \mathrm{mg} . \mathrm{L}^{-1}, 4000 \mathrm{mg} . \mathrm{L}^{-1}$ e $6000 \mathrm{mg} \cdot \mathrm{L}^{-1}$ de AIA, dissolvidos em meio hidroalcoólico (50\% água e $50 \%$ de álcool). Foram utilizadas 5 repetições e 10 estacas por unidade experimental.

As estacas foram colocadas em tubetes de polipropileno de $180 \mathrm{~cm}^{3}$, contendo vermiculita de granulometria média e substrato comercial $(1: 1 \mathrm{v} / \mathrm{v})$. O substrato comercial para plantas misto $\left(\right.$ Tecnomax $\left.^{\circledR}\right)$, segundo o fabricante, é composto por turfa, vermiculita expandida, casca de pínus e carvão vegetal. As características descritas na embalagem do produto são: $\mathrm{pH}=6,0( \pm 0,5)$; condutividade elétrica $=0,7( \pm 0,3) \mathrm{mS} \cdot \mathrm{cm}^{-1} ;$ densidade $=500 \mathrm{~kg} \cdot \mathrm{m}^{-3}$; capacidade de retenção de água $(\mathrm{CRA})$ $(\mathrm{p} / \mathrm{p})=150 \%$; e umidade máxima $(\mathrm{p} / \mathrm{p})=50 \%$. A vermiculita expandida de granulometria média possui $\mathrm{pH}=7,0( \pm 0,5)$; condutividade elétrica $=0,7( \pm 0,5) \mathrm{mS} \cdot \mathrm{cm}^{-1}$; densidade $=80 \mathrm{~kg} \cdot \mathrm{m}^{-3}$; capacidade de retenção de água $(\mathrm{CRA})=60 \%$; e umidade máxima $=10 \%$.

As bandejas contendo os tubetes com as estacas foram acondicionadas em casa de vegetação, com temperatura entre 20 e $30{ }^{\circ} \mathrm{C}$ e irrigação por microaspersão, permanecendo até a avaliação do enraizamento (160 dias). Após o período de enraizamento, o material foi transferido para a casa de sombra, visando à aclimatação (50\% de sombreamento e irrigação por microaspersão), permanecendo em torno de 30 dias, e em seguida foram transferidas para a área de pleno sol por mais 30 dias, visando a rustificação das mudas, sendo expostas diretamente ao sol e com irrigação diária, realizada manualmente.

Após a rustificação, quando as mudas estavam com 220 dias após o estaqueamento e prontas para o plantio a campo (aproximadamente 25 a $30 \mathrm{~cm}$ de altura), as mudas foram transferidas para vasos de polietileno com $4 \mathrm{~L}$ de capacidade. $\mathrm{O}$ substrato utilizado foi formado pela mistura de $70 \%$ de substrato comercial Plantmax $^{\circledR}$ (descrito anteriormente) e $30 \%$ de vermiculita de granulometria média. Sete dias depois do transplante para os vasos, as mudas tiveram a parte aérea podada a aproximadamente 10 a $15 \mathrm{~cm}$ do nível do substrato, visando estimular a ocorrência de brotações laterais e formar as minicepas e, posteriormente, o minijardim clonal.

O minijardim clonal foi instalado em estufa coberta por polietileno fixo na parte superior (no teto) e retrátil nas laterais. Em dias quentes, as laterais eram abertas, para evitar temperaturas muito altas no interior da estrutura. O manejo do minijardim clonal constituiu-se, principalmente, de irrigações e fertilizações com macro e micronutrientes, visando manter o turgor hídrico e o status nutricional adequado das minicepas para produção de material vegetativo (miniestacas). A solução nutritiva utilizada foi à base do fertilizante comercial Forth Solúvel Inicial ${ }^{\circledR}$, composto por $10 \% \mathrm{~N}$ (solúvel em água), $42 \%$ $\mathrm{P}_{2} \mathrm{O}_{5}$ (solúvel em água), $10 \% \mathrm{~K}_{2} \mathrm{O}$ (solúvel em água), $0,6 \% \mathrm{Mg}, 0,1 \% \mathrm{Fe}$ e $0,02 \mathrm{Br}$. A fertirrigação foi realizada duas vezes por semana, em que cada minicepa recebeu $50 \mathrm{ml}$ da solução composta pela diluição de 1,5 gramas do fertilizante por litro de água. 
A contagem das miniestacas era efetuada sempre que as brotações das minicepas atingiam tamanho ideal para a miniestaquia. Dessa forma, não foi estabelecido um intervalo fixo entre as sucessivas coletas. Em cada intervenção, todas as brotações que apresentavam tamanho suficiente para serem enquadradas nos padrões de miniestaca (acima de $5 \mathrm{~cm}$ ) eram coletadas. $O$ minijardim clonal foi estabelecido em delineamento inteiramente casualizado (DIC), com 8 repetições de 6 minicepas cada.

Do resgate vegetativo foi verificada a emissão de brotações das árvores decepadas e posterior contagem do número de brotos por indivíduo que apresentou brotação. No experimento de enraizamento de estacas, foi realizada avaliação aos 160 dias após estaqueamento, observando-se porcentagem de sobrevivência (estacas que apresentavam lenho vivo, folhas velhas ou brotações jovens), porcentagem de estacas que apresentavam calos (formação de estruturas calogênicas na base da estaca), porcentagem de estacas enraizadas e número total de raízes emitidas e comprimento de raiz (raízes com comprimento mínimo de $1 \mathrm{~mm}$ ). As mudas no processo de aclimatação foram avaliadas quanto à sobrevivência (\%), e no minijardim clonal as minicepas foram avaliadas quanto à mortalidade (\%) e à produção de miniestacas.minicepa ${ }^{-1}$.

As variâncias dos tratamentos foram testadas quanto à homogeneidade pelo teste de Bartlett. Quando constatada homogeneidade das variâncias, os dados eram submetidos à análise de variância, e quando houve diferença significativa pelo teste de F, houve aplicação de teste de Scott-Knott ou regressão polinomial ao nível de 5\% de probabilidade. A análise dos dados foi realizada no pacote estatístico SISVAR (FERREIRA, 2011). Os gráficos foram desenvolvidos em Microsoft Excel.

\section{RESULTADOS E DISCUSSÕES}

\section{Resgate e influência do AIA na estaquia}

Em relação aos indivíduos de sequoias em que foi realizado o corte raso, três apresentaram emissão de brotações e dois indivíduos não apresentaram qualquer indicio de brotos após cinco meses da recepa. As brotações emitidas apresentaram em média $50 \mathrm{~cm}$ de altura e a quantidade de brotos variou com o indivíduo (4 a 15). Esse resultado confirma a capacidade que a sequoia tem de emitir brotações (LUNA, 2008), principalmente em regiões mais basais na planta (POWER et al., 1988). Dessa forma, pode-se dizer que a decepa dos indivíduos é uma boa alternativa para o resgate de material juvenil de árvores adultas (HACKETT, 1987; SANTIN et al., 2008).

Segundo Denlay (2007), em um jardim clonal a campo de sequoia localizado na Califórnia (EUA), árvores com menos de 10 anos de idade são podadas e brotações são coletadas anualmente, com um tamanho de 7,5 a $10 \mathrm{~cm}$. Para a obtenção de um menor índice de mortalidade, são preferidas estacas com a base na coloração marrom e a ponteira verde. Em estudo com Cupressus lusitanica Mill, outra conífera, mais conhecida e plantada no Brasil, Kratz et al. (2010) não obtiveram brotações em árvores com 10 anos de idade após corte raso das plantas, somente foram identificadas brotações em árvores com 5 anos de idade, mesmo assim com brotações muito pequenas (média de 1,0 cm).

$\mathrm{O}$ corte raso da sequoia se mostrou uma técnica promissora no resgate vegetativo e no revigoramento de material para ser utilizado na propagação por estaquia. O rejuvenescimento através da decepa é uma das melhores formas de se obter o rejuvenescimento em espécies do gênero Sequoia e Sequoiadendron (HARTMANN et al., 2011). Tredici (1999) também comenta que em sequoia pode haver uma zona extrema de juvenilidade, chamada de lignotuber, provocando a formação em massa de brotos na porção inferior no tronco.

Segundo Higashi et al. (2000), a decepa é uma técnica de resgate vegetativo bastante utilizada no Brasil, principalmente com Eucalyptus, devido sobretudo ao grau de rejuvenescimento conseguido nas brotações e ao grande número de brotações que surgem ao longo principalmente da cepa remanescente, quando comparada a outras técnicas de resgate. No entanto, a implementação dessa técnica depende da espécie, da época do ano e das condições ambientais e fisiológicas da planta (XAVIER et al., 2013), não havendo relatos da técnica em sequoia no Brasil.

A sobrevivência das estacas aos 160 dias após o estaqueamento foi alta para todos os tratamentos, não sendo observada diferença estatística, com média de $97,1 \%$. Essa sobrevivência elevada das estacas pode ser resultado das boas condições climáticas durante a realização do experimento e também da boa capacidade da espécie em sobreviver após a confecção das estacas. Esse resultado provavelmente ocorreu em função de as estacas apresentarem alta lignificação dos tecidos, conteúdo de 
carboidratos, aminoácidos e de outras substâncias, como auxinas, que serviram como reserva energética (HARTMANN et al., 2011). Luna (2008) comenta que estacas de sequoias maiores e com tecidos lignificados apresentam maior capacidade de sobreviver e enraizar do que estacas muito tenras.

Outro motivo que pode ter auxiliado na sobrevivência das estacas foi a presença de calos na base, os quais podem, durante algum tempo, realizar a função das raízes, ou seja, absorção de água e sais minerais (HARTMANN et al., 2011). A totalidade das estacas que sobreviveram apresentaram formação de calos, independentemente da presença ou concentração de AIA. O calo é uma massa irregular de células parenquimáticas em diversos estados de lignificação que geralmente se desenvolvem na base das estacas quando colocadas em condições ambientais favoráveis ao enraizamento, havendo relatos de que as primeiras raízes aparecem com frequência através do calo, conduzindo à suposição de que a formação do calo é essencial para o enraizamento em algumas espécies (THOMAS et al., 2003).

Para sequoia, foi observado que todas as estacas que desenvolveram raízes apresentaram calos nas proximidades do corte (Figura 1A), não havendo a formação direta de raízes na ausência do calo. Segundo Hartmann et al. (2011), as raízes de estacas de sequoia normalmente surgem de tecidos calogênicos externos, a exemplo de outros gêneros de coníferas, como Cryptomeria, Larix, Podocarpus e Taxodium.

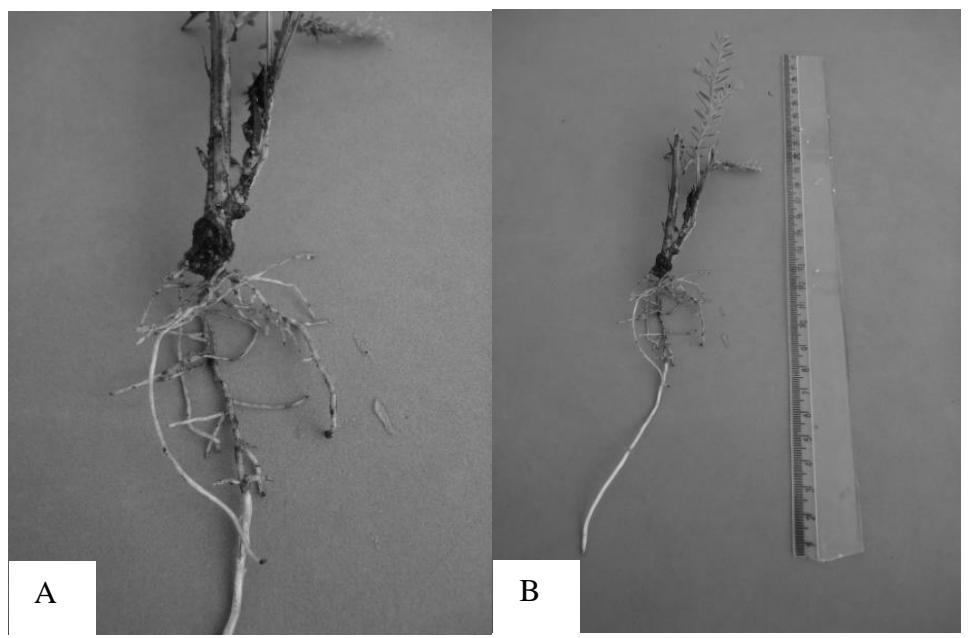

Figura 1. Formação de raízes oriundas dos calos formados (A) e aspecto de estaca enraizada (B) de Sequoia sempervirens submetida a diferentes concentrações de ácido indolacético (AIA).

Figure 1. Formation of roots coming from the calluses (A) and appearance of rooted cutting (B) Sequoia sempervirens subjected to different concentrations of indole acetic acid (IAA).

Esse fato foi comentado por Hartmann et al. (2011), que relatam que em algumas espécies a formação de calo é um precursor da formação de raízes adventícias. Além disso, conforme os mesmos autores, a formação de calos pode ser benéfica em plantas que enraízam lentamente, como a sequoia, pois proporciona uma capa protetora que retarda o aparecimento da podridão.

Foi obtida diferença significativa $(p<0,05)$ entre as doses de AIA e as variáveis porcentagem de enraizamento, número de raízes por estaca e comprimento médio das raízes. Em relação ao enraizamento das estacas (Figura 1B) em função das concentrações de AIA, houve um comportamento quadrático

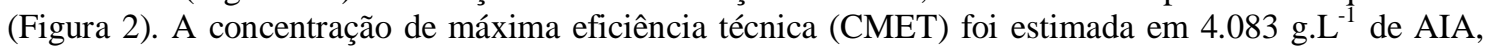
correspondendo a uma taxa de enraizamento de $80,9 \%$ e um acréscimo de $42 \%$ em relação à testemunha (ausência de AIA). O uso da maior dosagem de AIA testada (6000 g. $\left.\mathrm{L}^{-1}\right)$ provocou redução no enraizamento.

Esse resultado demonstra que a aplicação de auxina exógena é fundamental para elevar a porcentagem de enraizamento de estacas de sequoia. Os ganhos advindos da aplicação dos reguladores de crescimento têm sido mais frequentes em materiais com maior dificuldade de enraizamento, seja por questões genéticas ou em função do estágio de maturação dos propágulos (XAVIER et al., 2013).

É importante ressaltar que mesmo sem a aplicação do AIA houve considerável enraizamento das estacas (39\%), mostrando que o rejuvenescimento através da decepa dos indivíduos foi importante no 
para obtenção da juvenilidade, interessante para se obter maior enraizamento (HARTMANN et al., 2011). A concentração de $6000 \mathrm{mg} . \mathrm{L}^{-1}$ de AIA provocou queda no enraizamento das estacas. Esse fato possivelmente está relacionado ao efeito fitotóxico que a auxina pode ter em concentrações mais elevadas (ROCHA et al., 2004).

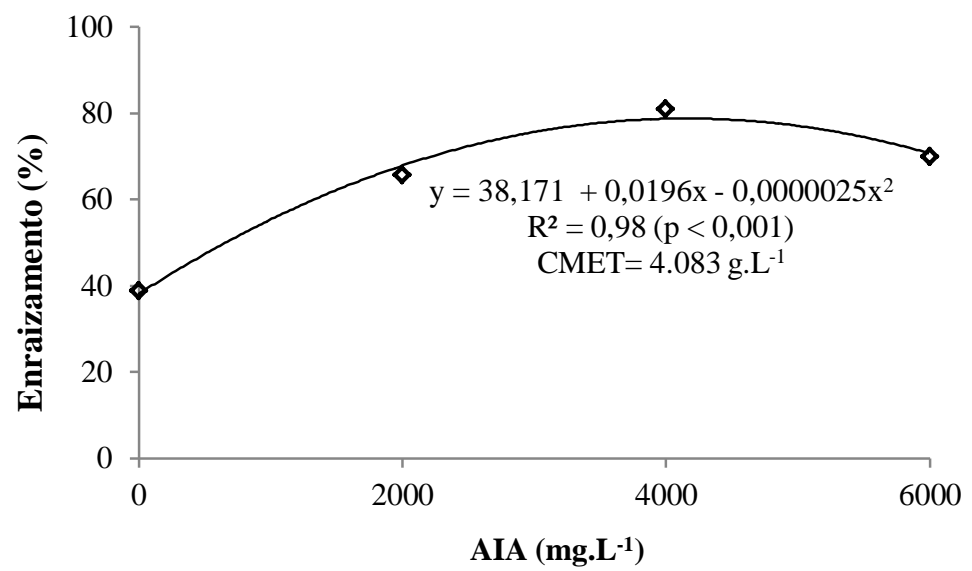

Figura 2. Enraizamento (\%) de estacas de Sequoia sempervirens em função de concentrações de ácido indolacético (AIA).

Figure 2. Rooting cuttings (\%) of Sequoia sempervirens in terms of concentrations indoleacetic acid (IAA).

Tão importante quanto a concentração dos reguladores de crescimento na indução da rizogênese adventícia é a existência de um adequado balanço hormonal endógeno, especialmente entre auxinas, giberelinas e citocininas, ou seja, um equilíbrio entre promotores e inibidores do processo de iniciação radicular (OSTERC; STAMPAR, 2009; COSTA et al., 2013). A maneira mais comum de promover esse equilíbrio é pela aplicação exógena de reguladores de crescimento sintéticos, como AIA e AIB, que podem elevar o teor de auxina nos tecidos (GONTIJO et al., 2003).

Além disso, o sucesso de enraizamento é influenciado por uma série de outros fatores, como os minerais, os hidratos de carbono, a sazonalidade, o estado de maturação das árvores-matrizes e outros componentes bioquímicos, tais como compostos fenólicos (COSTA et al., 2013). A resposta dos tecidos à auxina pode ser regulada por fatores como a sensibilidade de uma célula ao sinal da auxina (STEWART; NEMHAUSER, 2010) e a concentração de fatores inibitórios ao enraizamento na base das estacas (FORD et al., 2002).

Os índices de enraizamento obtidos neste estudo são superiores aos encontrados por Denlay (2007), o qual, em tratamento de estacas de sequoia com $1.000 \mathrm{mg} . \mathrm{L}^{-1}$ de AIB, atingiu 25 a $30 \%$ de enraizamento. Segundo os autores, as estacas permanecem por aproximadamente oito meses em casa de vegetação para ocorrer o enraizamento. O tempo de cinco meses para ocorrer o enraizamento obtido neste estudo é igual ao registrado por Luna (2008), no qual o enraizamento de estacas de sequoia atingiu entre 30 a $35 \%$ de enraizamento utilizando enraizador comercial (Hormex®).

O AIA também apresentou influência em relação ao número de raízes (Figura 3A) e comprimento de raízes (Figura 3B). O máximo número de raízes foi estimado em 3.571 g.L ${ }^{-1}$ de AIA, correspondendo a uma formação de 2,25 raízes por estaca e um acréscimo de $43 \%$ em relação à testemunha (ausência de AIA). Com o aumento da concentração de AIB, foi verificada queda na formação de raízes, possivelmente em função da fitotoxicidade da auxina.

O comprimento das raízes tendeu a aumentar com a concentração de AIA até 4.090 g.L $\mathrm{L}^{-1}$, na qual atingiu o máximo comprimento, diminuindo após com a concentração de 6.000 g. $\mathrm{L}^{-1}$. O máximo comprimento obtido na CMET foi $65 \%$ superior ao tratamento em que não foi aplicada a auxina.

A auxina, além de aumentar a porcentagem de estacas enraizadas, promoveu melhoria do sistema radicular formado. Concordando com esses resultados, Bastos et al. (2005) mencionam que o uso de reguladores de crescimento tem por finalidade acelerar a iniciação radicular, aumentar o número e a qualidade das raízes formadas e uniformizar o enraizamento. 

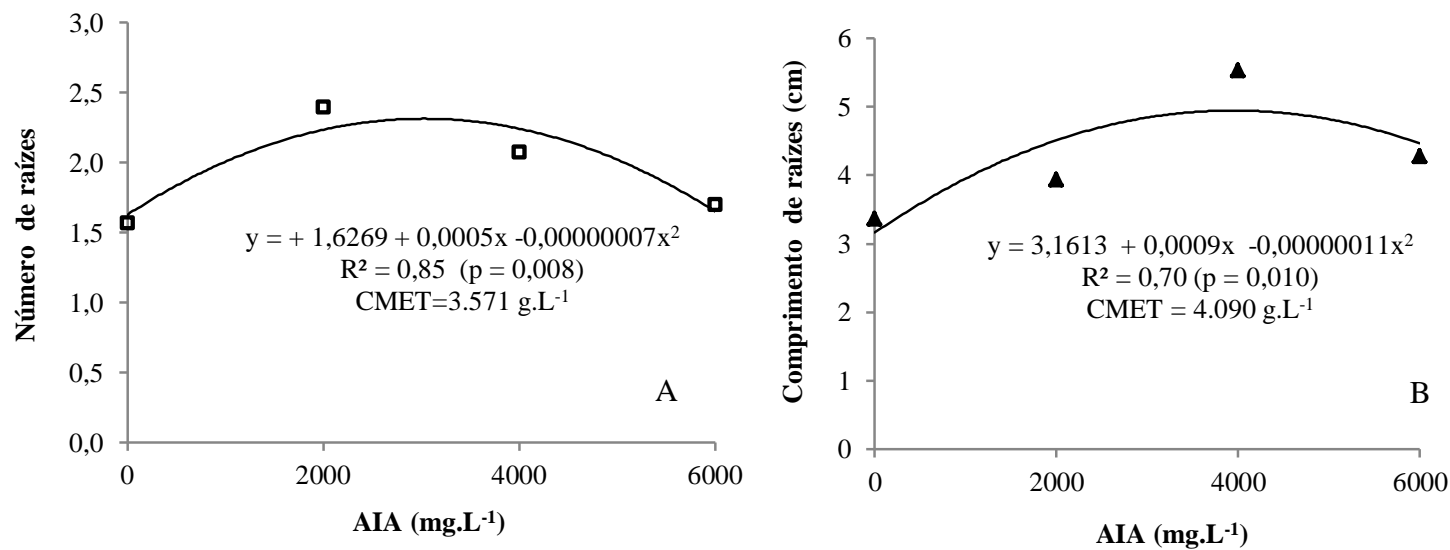

Figura 3. Número de raízes (A) e comprimento de raízes (B) em estacas de Sequoia sempervirens em função de concentrações de ácido indolacético (AIA).

Figure 3. Number of roots (A) and length of roots (B) in cuttings of Sequoia sempervirens in terms of concentrations of indoleacetic acid (IAA).

Na propagação vegetativa, além da porcentagem de enraizamento, o número de raízes formadas nas estacas é uma das variáveis mais relevantes na produção de mudas (ANTUNES et al., 1996). Uma melhor resposta para essas variáveis indica que as mudas posteriormente formadas possuirão um melhor desenvolvimento, uma vez que o melhor sistema radicial resultará em maiores chances de sobrevivência quando transplantadas para o campo (REIS et al., 2000). Essas variáveis são bastante importantes no processo de estaquia da sequoia, pois, segundo Luna (2008), mesmo apresentando enraizamento, estacas de sequoia podem apresentar alta mortalidade no processo de aclimatação, devendo-se tomar cuidado com condições ambientais, principalmente em relação a altas temperaturas. Neste estudo, foi observada alta taxa de sobrevivência das mudas na etapa de aclimatação (95\%), mostrando que o sistema radicular formado foi de boa qualidade e suficiente para o estabelecimento das mudas.

\section{Minijardim clonal}

A implantação do minijardim clonal de sequoia apresentou uma mortalidade de $25 \%$ das minicepas implantadas após oito meses do transplante para os vasos e três coletas realizadas de miniestacas. Na primeira coleta foi observada a maior mortalidade (Tabela 1), reduzindo com as coletas seguintes. Essa elevada mortalidade ocorrida até a primeira coleta pode estar relacionada à dificuldade da espécie na aclimatação, mesmo após o enraizamento e aclimatação em pleno sol, e também na adaptação das minicepas ao sistema de minijardim clonal, principalmente em relação à nutrição utilizada. Na terceira coleta, praticamente não houve mortalidade das minicepas $(3,0 \%)$, demonstrando uma adaptação ao sistema e principalmente em relação à solução nutritiva. Recomenda-se testar novas formulações, buscando-se diminuir essa elevada mortalidade inicial, de modo a diminuir as perdas e elevar a quantidade de mudas formadas posteriormente.

Tabela 1. Mortalidade de minicepas (\%) e produtividade de miniestacas.minicepa ${ }^{-1}$ de Sequoia sempervirens em função das coletas realizadas no sistema de minijardim clonal em vasos.

Table 1. Ministumps mortality (\%) and productivity of cuttings.ministump ${ }^{-1}$ of Sequoia sempervirens in terms of collections in mini-clonal hedge in pots.

\begin{tabular}{lcc}
\hline Coleta & Mortalidade (\%) & Produtividade de miniestacas.minicepa $^{-1}$ \\
\hline $1^{\mathrm{a}}$ coleta (jul/2013) & $15,0 \mathrm{~b}^{*}$ & 3,7 \\
$2^{\mathrm{a}}$ coleta (set/2013) & $7,0 \mathrm{a}$ & 4,4 \\
$3^{\mathrm{a}}$ coleta (nov/2013) & $3,0 \mathrm{a}$ & 5,4 \\
\hline * Médias seguidas pela mesma letra minúscula na coluna não diferem entre si pelo teste Scott-Knott a 5\% de probabilidade de erro.
\end{tabular}

A produção de miniestacas foi bastante variável após três coletas realizadas, variando entre 1 e 8 miniestacas obtidas por cepa-matriz (minicepa). Em média, a produção foi de 4,5 miniestacas.minicepa ${ }^{-1}$ por coleta, não apresentando diferença entre as coletas. Contudo, observa-se uma tendência de elevação com o passar das coletas, possivelmente pela adaptação das minicepas ao minijardim e também pela

FLORESTA, Curitiba, PR, v. 45, n. 2, p. 383 - 392, abr. / jun. 2015.

Navroski, M. C. et al.

ISSN eletrônico 1982-4688 / ISSN impresso 0015-3826

389

DOI: $10.5380 /$ rf.v45i2.35407 
elevação da temperatura no período, já que as coletas ocorreram ao final do inverno ( $2^{\mathrm{a}}$ coleta) e primavera ( $3^{\mathrm{a}}$ coleta). Esses resultados de produção de miniestacas mostram a potencialidade para a produção de mudas clonais através do sistema de minijardim clonal.

A figura 4 apresenta uma minicepa de sequoia com as brotações aptas para a coleta e confecção de miniestacas. O uso de minijardim clonal para produção de mudas de sequoia foi relatado por Luna (2008). Segundo o autor, as estacas produzidas por esse sistema enraízam com maior facilidade, apresentando em torno de 30 a $35 \%$ de enraizamento sem o uso de qualquer tipo de regulador de crescimento. O cultivo em minijardim é apontado por muitos autores como uma forma de manutenção da juvenilidade, principalmente em espécies coníferas podadas continuamente no sistema de minijardim clonal (BONGA; ADERKAS, 1993; HAMANN, 1998; AIMERS-HALLIDAY et al., 2003). Entretanto, alguns estudos mostraram que esse sistema pouco faz para aliviar os efeitos da maturação e que o enraizamento de estacas pode continuar em declínio com o aumento da idade da minicepa (McGRANAHAN et al., 1999; MITCHELL et al., 2004).

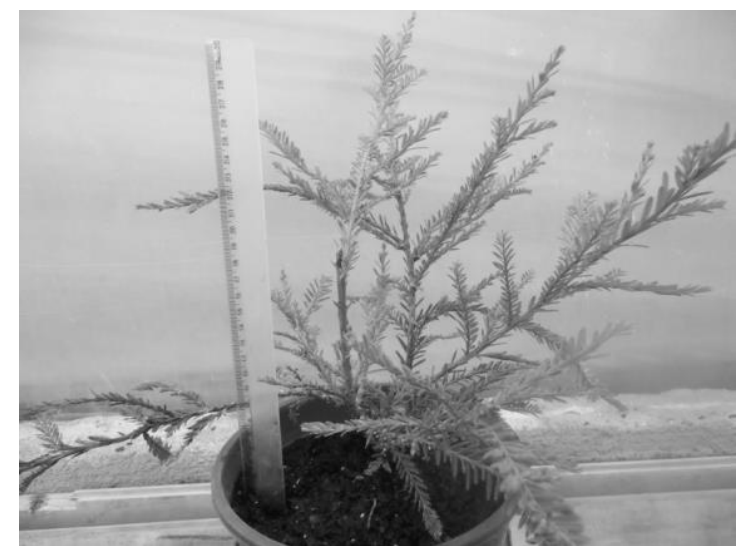

Figura 4. Minicepa de Sequoia sempervirens cultivada em minijardim em vaso para produção de miniestacas.

Figure 4. Sequoia sempervirens ministump cultivated in mini-clonal hedge for the production of potted cuttings.

O intervalo médio entre as três sucessivas coletas de miniestacas nas minicepas de sequoia no minijardim clonal em vasos foi de 60 dias. A variação no intervalo entre coletas é comumente observada em sistemas de minijardins clonais e pode variar em função do tipo de minijardim, da temperatura, da intensidade luminosa, da espécie em estudo e da nutrição mineral específica (HIGASHI et al., 2002).

De maneira geral, o intervalo entre coletas no minijardim clonal é muito variável. Mesmo dentro do gênero Eucalyptus, o intervalo pode variar entre 8 e 21 dias (BRONDANI et al., 2010). Para sequoia, mais coletas devem ser realizadas para se determinar o momento adequado das coletas, definindo o ponto ideal da miniestaca, para não prejudicar a minicepa quanto a produtividade, sobrevivência e enraizamento das miniestacas obtidas.

\section{CONCLUSÕES}

- O resgate vegetativo através da decepa de árvores apresenta potencial para produção de estacas de sequoia e revigoramento do material. $\mathrm{O}$ uso do AIB aumenta a porcentagem de enraizamento e também a qualidade das mudas formadas, através do aumento do número e comprimento de raízes. O minijardim clonal de sequoia é uma boa opção para a multiplicação clonal da espécie, com grande potencial para uso extensivo.

\section{REFERÊNCIAS}

AIMERS HALLIDAY, J.; MENZIES, M. I.; FAULDS, T.; HOLDEN, D. G.; LOW, C. B.; DIBLEY, M. J. Nursery systems to control maturation in Pinus radiata cuttings, comparing hedging and serial propagation. New Zealand Journal of Forestry Science, n. 33, p. 135 - 155. 2003. 
ANTUNES, J. A. S.; HOFFMANN, A.; RAMOS, J. D.; CHALFUN, N. N. J.; OLIVEIRA JÚNIOR, A. F. Efeito do método de aplicação e de concentrações do ácido indolbutírico no enraizamento de estacas semilenhosas de Pyrus calleryana. Revista Brasileira de Fruticultura, Cruz das Almas, v. 18, n. 3, p. 371 - 376, 1996.

BASTOS, D. C.; PIO, R., FILHO, J. A. S.; LIBARDI, M. N.; ALMEIDA, L. F. P.; ENTELMANN, F. A. Enraizamento de estacas lenhosas e herbáceas de cultivares de caquizeiro com diferentes concentrações de ácido indolbutírico. Revista Brasileira de Fruticultura, Jaboticabal, n. 27, p. 182 - 184, 2005.

BOE, K. N. Sequoia sempervirens (D. Don) Endl. In: SCHOPMEYER, C. S. (Ed.). Seeds of woody plants in the United States. Agriculture Handbook 450. USDA Forest Service, Washington, DC, USA, 1974. p. 764 - 766.

BONGA, J. M.; ADERKAS, P. Rejuvenation of tissues from mature conifers and its implications for propagation in vitro. In: AHUJA, M. R.; LIBBY, W. J. (Ed.). Clonal Forestry I, Genetics and Biotechnology, Springer-Verlag, Berlim, 1993. p 182 - 199.

BRONDANI, G. E.; WENDLING, I.; GROSSI, F.; DUTRA, L. F.; ARAÚJO, M. A. Miniestaquia de Eucalyptus benthamii x Eucalyptus dunnii: (II) sobrevivência e enraizamento de miniestacas em função das coletas e estações do ano. Ciência Florestal, Santa Maria, v. 20, n. 3, p. 453 - 465, 2010.

COSTA, C. T.; DE ALMEIDA, M. R.; RUEDELL, C. M.; SCHWAMBACH, J.; MARASCHIN, F. S.; FETT-NETO, A. G. When stress and development go hand in hand: main hormonal controls of adventitious rooting in cuttings. Frontiers in Plant Science, California, n. 4, p. 1 - 19, 2013.

COWN, D. Redwood in New Zealand - an end-user perspective. NZ Journal of Forestry, Rotorua, v. 52 , n. 4 , p. $35-41,2008$.

DENLAY, T. Personal communication. Azusa (CA): Monrovia Nursery. Plant Propagation Coach. 2007.

FERREIRA, D. F. Sisvar: a computer statistical analysis system. Ciência e Agrotecnologia, Lavras, v. 35, n. 6, p. 1039 - 1042, 2011.

FORD, Y. Y.; BONHAM, E. C.; CAMERON, R. W. F.; BLAKE, P. S.; JUDD, H. L.; HARRISONMURRAY, R. S. Adventitious rooting: examining the role of auxin in an easy-and a difficult-to-root plant. Plant Growth Regulation, n. 36, p. 149 - 159, 2002.

FRITZ, E. Some principles govering the growing of redwood crops. FORTY-FIRST ANNUAL CONFERENCE OF THE WESTERN FORESTRY AND CONSERVATION ASSOCIATION. San Francisco, CA; Portland (OR): Western Forestry and Conservation Association. Proceedings... p. 23 25,1950 .

GONTIJO, T. C. A.; RAMOS, J. D.; MENDONÇA, V.; PIO, R.; NETO, S. E. A.; CORRÊA, F. L. O. Enraizamento de diferentes tipos de estacas de aceroleira utilizando ácido indolbutírico. Revista Brasileira de Fruticultura, Jaboticabal, n. 25, p. 290 - 292. 2003.

HACKETT, W. P. Donor plant maturation and adventitious root formation. In: DAVIES, T. D.; HAISSIG, B. E.; SANKHLA, N. (Eds.). Adventitious root formation in cuttings. Portland: Dioscorides Press, 1987. p. $11-28$.

HAMANN, A. Adventitious root formation in cuttings of loblolly pine (Pinus taeda L.): developmental sequence and effects of maturation. Trees, Vancouver, n. 12, p. 175 - 180, 1998.

HARTMANN, H. T.; KESTER, D. E.; DAVIES JR., F. T.; GENEVE, R. L. Hartmann and Kester's Plant Propagacion: principles and practices. 8. ed. New Jersey: Prentice Hall, 2011. 915 p.

HIGASHI, E. N.; SILVEIRA, R. L. V. A.; GONÇALVES, A. N. Propagação vegetativa de Eucalyptus: princípios básicos e a sua evolução no Brasil. Circular Técnica IPEF, Piracicaba, n. 192, p. 1 - 14, 2000.

. Nutrição e adubação em minijardim clonal hidropônico de Eucalyptus. Circular Técnica IPEF, Piracicaba, n. 194, p. 1 - 21, 2002.

KRATZ, D.; WENDLING, I.; BRONDANI, G. E.; DUTRA, L. F. Propagação assexuada de Cupressus lusitanica. Pesquisa Florestal Brasileira, Colombo, v. 30, n. 62, p. 161 - 164, 2010.

FLORESTA, Curitiba, PR, v. 45, n. 2, p. 383 - 392, abr. / jun. 2015.

Navroski, M. C. et al.

ISSN eletrônico 1982-4688 / ISSN impresso 0015-3826

DOI: $10.5380 /$ rf.v45i2.35407 
LINHART, Y. B.; LIBBY, W. J. Vegetative propagation of coast redwood. Berkeley (CA): University of California, Berkeley. 10 p. 1965.

LIU, C.; YIN, X. X. Y.; HUANG, L.; ZHOU, J. Shoot regeneration and somatic embryogenesis from needles of redwood (Sequoia sempervirens (D.Don.) Endl.). Plant Cell Reports, Bruxelas, v. 25, p. 621 628, 2006.

LUNA, T. Vegetative Propagation Of Coastal Redwood (Sequoia sempervirens (Lamb. ex D.Don) Endl.). Native Plants Journal, Washington, v. 9, n. 1, p. 25 - 28, 2008.

MARCHIORI, J. N. C. Dendrologia das Gimnospermas. Santa Maria: Ed. UFSM, 1996, 160 p.

MCGRANAHAN, M. F.; BORALHO, N. M. G.; GREAVES, B. L. Genetic control of propagation effects and the importance of stock plant age and source on early growth in cuttings of Pinus radiata. Silva e Genetic, Bremen, n. 48, p. 267 - 272, 1999.

METCALF, W. Artificial reproduction of redwood. Journal of Forestry, Bethesda, v. 22, p. 873 - 893, 1924.

MITCHELL, R. G.; ZWOLINSKI, J.; JONES, N. B. The effects of ontogenetic maturation in Pinus patula Part I: nursery performance. South African Forest Journal, Grahamstown, n. 202, p. 29 - 36, 2004.

OLSON, D. F.; ROY, D. F.; WALTERS, G. A. Sequoia sempervirens (D.Don) Endl. redwoods. In: BURNS, R. M.; HONKALA, B. H. (Eds.). Silvics of North America. U.S. Department of Agriculture, Agricultural Handbook, 1990. p. 541 - 551.

OSTERC, G.; STAMPAR, F. Juvenile stockplant material enhances root development through higher endogenous auxin level. Acta Physiologiae Plantarum, Poznan, n. 31, p. 899 - 903, 2009.

PIIRTO, D. D. Wood of Giant sequoia: properties and unique characteristics. WORKSHOP ON MANAGEMENT OF GIANT SEQUOIA; May 24-25, 1985; Reedley, California. Gen. Tech. Rep. PSW95. Berkeley, CA: Pacific Southwest Forest and Range Experiment Station, Forest Service, U.S. Department of Agriculture. Proceedings... 1986: 19-23.

POWER, A. R.; DODD, R. S.; LIBBY, W. J. Cyclophysis and topophysis in coast redwood stecklings. Silva e Genética, Bremen, v. 37, n. 1, p. 8 - 14, 1988.

REIS, J. M. R.; CHALFUN, N. N. J.; LIMA, L. C. O.; LIMA, L. C. Efeito do estiolamento e do ácido indolbutírico no enraizamento de estacas do porta-enxerto Pyrus calleryana Dcne. Ciência e Agrotecnologia, Lavras, v. 24, n. 4, p. 931 - 938, 2000.

ROCHA, S. C.; QUEIROZ, J. A. L.; ZUFFELLATO-RIBAS, K. C. Propagação vegetativa de espirradeira pela técnica da estaquia. Scientia Agraria, Curitiba, v. 5, n. 1 - 2, p. 73 - 77, 2004.

SANTIN, D.; WENDLING, I.; BENEDETTI, E. L.; BRONDANI, G. E.; REISSMANN, D. M.; ROVEDA, L. F. Poda e anelamento em erva-mate (Ilex paraguariensis) visando à indução de brotações basais. Pesquisa Florestal Brasileira, Colombo, n. 56, p. 97 - 104, 2008.

STEWART, J. L.; NEMHAUSER, J. L. Do trees grow on money? Auxin as the currency of the cellular economy. Cold Spring Harbor Perspectives in Biology, Bethesda, n. 2, p. 2 - 14, 2010.

THOMAS, P.; LEE, M. M.; SCHIEFELBEIN, J. Molecular identification of proline-rich protein genes induced during root formation in grape (Vitisvinifera L.) stem cuttings. Plant, Cell and Environment, Malden, n. 26, p. 1497 - 1504, 2003.

TREDICI, P. D. Redwood burls: immortality underground. Arnoldia, Cambridge, n. 59, v. 3, p. 14 - 22, 1999.

VERÍSSIMO, V.; HERTER, F. G.; RODRIGUES, A. C.; TREVISAN, R.; MARAFON, A. C. Níveis de cálcio e boro de gemas florais de pereira (Pyrus sp.) no Sul do Brasil. Revista Brasileira de Fruticultura, Jaboticabal, v. 28, n. 1, p. 28 - 31, 2006.

XAVIER, A.; WENDLING, I.; SILVA, R. L. Silvicultura clonal: princípios e técnicas. Viçosa: UFV, 2013. $279 \mathrm{p}$. 